\title{
CFD simulations of the aerodynamic drag of two drafting cyclists
}

\author{
Bert Blocken $^{\mathrm{a}, *}$, Thijs Defraeye ${ }^{\mathrm{b}}$, Erwin Koninckx ${ }^{\mathrm{c}}$, Jan Carmeliet ${ }^{\mathrm{d}, \mathrm{e}}$, Peter Hespel ${ }^{\mathrm{f}}$ \\ ${ }^{a}$ Building Physics and Services, Eindhoven University of Technology, P.O. Box 513, 5600 Eindhoven, The \\ Netherlands \\ ${ }^{b}$ MeBioS, University of Leuven, Willem de Croylaan 42, Leuven, Belgium \\ ${ }^{c}$ Flemish Cycling Federation, Globelaan 49/2, 1190 Brussels, Belgium \\ ${ }^{d}$ Chair of Building Physics, Swiss Federal Institute of Technology Zurich (ETHZ), Wolfgang-Pauli-Strasse 15, \\ 8093 Zürich, Switzerland \\ ${ }^{e}$ Laboratory for Building Science and Technology, Swiss Federal Laboratories for Materials Testing and \\ Research (Empa), Überlandstrasse 129, 8600 Dübendorf, Switzerland \\ ${ }^{f}$ Bakala Academy - Athletic Performance Center, Department of Biomedical Kinesiology, University of Leuven, \\ Tervuursevest 101, 3001 Heverlee, Belgium
}

\section{Research highlights:}

- High-resolution grids with wall-adjacent cell centres at 15 micrometer from the body surface

- Validation with wind-tunnel measurements of drag force of single cyclist and two cyclists.

- CFD simulations and measurements show that drafting provides drag reduction for both cyclists

- Drag reduction of leading cyclist due to trailing cyclist in his/her wake goes up to $2.6 \%$.

- The optimum strategy for team time trials should consider drafting effects of every team member.

\begin{abstract}
The aerodynamic drag of two drafting cyclists in upright position (UP), dropped position (DP) and time-trial position (TTP) is analysed by Computational Fluid Dynamics (CFD) simulations supported by wind-tunnel measurements. The CFD simulations are performed on high-resolution grids with grid cells of about 30 micrometer at the cyclist body surface, yielding $y^{*}$ values well below 5 . Simulations are made for single cyclists and for two drafting cyclists with bicycle separation distances (d) from $0.01 \mathrm{~m}$ to $1 \mathrm{~m}$. Compared to a single (isolated) cyclist and for $\mathrm{d}=0.01 \mathrm{~m}$, the drag reduction of the trailing cyclist is $27.1 \%, 23.1 \%$ and $13.8 \%$ for $\mathrm{UP}$, DP and TTP, respectively, while the drag reduction of the leading cyclist is $0.8 \%, 1.7 \%$ and $2.6 \%$ for UP, DP and TTP, respectively. The drag reductions decrease with increasing separation distance. Apart from the wellknown drag reduction for the trailing cyclist, this study also confirms and quantifies the drag reduction for the leading cyclist. This effect was also confirmed by the wind-tunnel measurements: for DP with $\mathrm{d}=0.15 \mathrm{~m}$, the measured drag reduction of the leading cyclist was $1.6 \%$ versus $1.3 \%$ by CFD simulation. The CFD simulations are used to explain the aerodynamic drag effects by means of the detailed pressure distribution on and around the cyclists. It is shown that both drafting cyclists significantly influence the pressure distribution on each other's body and the static pressure in the region between them, which governs the drag reduction experienced by each cyclist. These results imply that there is an optimum strategy for team time trials, which should be determined not only based on the power performance but also on the body geometry, rider sequence and the resulting aerodynamic drag of each team member. Similar studies can be performed for other sports such as skating, swimming and running.
\end{abstract}

\section{Keywords}

Computational Fluid Dynamics; wind tunnel; aerodynamic cycling resistance; bicycle aerodynamics; drafting; numerical simulation

\section{Introduction}

"The greatest potential for improvement in cycling speed is aerodynamic" [1]. At racing speeds (about $54 \mathrm{~km} / \mathrm{h}$ or $15 \mathrm{~m} / \mathrm{s}$ in time trails), the aerodynamic resistance or drag is about $90 \%$ of the total resistance [2-4]. Aerodynamic drag can be investigated by field tests, wind-tunnel measurements and numerical simulation by

\footnotetext{
* Corresponding author: Bert Blocken, Building Physics and Services, Eindhoven University of Technology, P.O.Box 513, 5600 MB Eindhoven, the Netherlands. Tel.: +31 (0)40 247 2138, Fax +31 (0)40 2438595

E-mail address: b.j.e.blocken@tue.nl
} 
Computational Fluid Dynamics (CFD). In recent years, several publications have reported detailed CFD simulations in cycling [5-9] and other sport disciplines [10-14].

While most aerodynamic studies in cycling focused on the aerodynamic drag of a single (isolated) cyclist, several efforts have also been made to assess the effects of "drafting" [2,15-22]. In drafting, two or more cyclists ride close behind each other to reduce aerodynamic drag. This way, the trailing cyclist can benefit from the low pressure area behind the leading cyclist. In the past, drafting has been investigated with field tests and windtunnel measurements on real and dummy cyclists. Also wind-tunnel measurements and CFD simulations on human body models using simplified geometric volumes such as cylinders have been made. Kyle [15] reported coast-down tests in which the leading cyclist was found to be unaffected by one or more cyclists drafting in his wake, but where the trailing cyclist consumed $33 \%$ less power output than the leading one at $40 \mathrm{~km} / \mathrm{h}$. Because the rolling resistance is unaffected by drafting, this corresponds to an aerodynamic improvement of $38 \%$. He also found that the drag reduction increased with decreasing distance between leading and trailing rider. From windtunnel runs and coast-down tests, Kyle and Burke [2] observed that air resistance is decreased about $40 \%$ for the drafting riders. McCole et al. [16] measured the $\mathrm{O}_{2}$ uptake of cyclists riding outdoors at speeds from 32 to 40 $\mathrm{km} / \mathrm{h}$. They found that drafting at $32 \mathrm{~km} / \mathrm{h}$ reduced $\mathrm{VO}_{2}$ (i.e. volume of $\mathrm{O}_{2}$ consumption) by $18 \%$, while drafting at 37 and $40 \mathrm{~km} / \mathrm{h}$ reduced $\mathrm{VO}_{2}$ more than $27 \%$. Wind-tunnel tests by Zdravkovich et al. [18] showed a maximum drag reduction of $49 \%$ with the trailing rider directly behind the leader, and a reduction of $37 \%$ at a safer $0.10 \mathrm{~m}$ lateral (staggered) position. Note that the focus of most of these studies was on the effects of the leading cyclist on the trailing cyclist, and not of the trailing one on the leading one. Concerning the latter aspect, Olds [19] provided the following statement:

"It has been suggested that riding close behind a leading cyclist will also assist the leading rider in that the low pressure area behind the cyclist will be "filled up" by the trailing rider. However, both Kyle (1979) and McCole et al. (1990) failed to find any measurable effect either in rolldown experiments or in field $\mathrm{VO}_{2}$ measurements.”

Wilson [1] addressed the complexity of drag effects of drafting by citing the studies by Hoerner [23] and Papadopoulos and Drela [24] on human body models with simplified geometries. For two disks with their surface oriented perpendicular to the approaching flow, the drag of the first (upstream) disk is not affected by the second disk, while the second disk is dragged along when within 1.5 diameters of the first disk. For two circular cylinders with their vertical axis perpendicular to the airflow and placed behind each other with a separation distance of about two diameters, the first cylinder experiences a reduction in drag of about $15 \%$, while the second cylinder has about zero drag. When the separation distance increases to four diameters, the benefit of the first cylinder reduces to zero, while the drag of the second is about $25 \%$ of the isolated value. Finally, for two streamlined (wing-shaped) bodies however, again with vertical axis perpendicular to the airflow, these effects could not be confirmed. However, the geometry of a human body is very different from these simple model shapes. Iniguez-de-la Torre and Iniguez [22] analysed the drag of a pair of elliptic-shaped cylinders in order to provide estimates of drag reduction in cycling, aimed in particular at the potential benefit for the front rider. Their computational study showed that the leading cylinder experiences a $5 \%$ benefit due to the artificial tail wind created by the team. They however correctly mentioned that a realistic analysis of the complex geometry of a cyclist would require 3D numerical fluid dynamics simulations.

This paper presents such 3D CFD simulations to analyse the aerodynamic drag effects of two drafting cyclists. To the best of our knowledge, CFD studies on drafting with real cyclist geometries have not yet been published. The main reason to apply CFD is that it simultaneously provides information on the aerodynamic drag and on the detailed airflow pattern around the cyclists, which can explain the drag mechanism and lead to increased insight in the fluid mechanics of drafting. Because the above-mentioned literature review seems to indicate some lack of consensus about the effect of the trailing cyclist on the leading cyclist, special attention will also be given to addressing and quantifying this effect.

\section{Wind-tunnel experiments}

\subsection{Wind-tunnel experiments for isolated cyclist}

The experiments were performed in the low-speed closed-circuit wind tunnel LST of the Dutch-German wind tunnels (DNW) in Marknesse, The Netherlands. The test section of the tunnel is $2.25 \mathrm{~m}$ high and $3 \mathrm{~m}$ wide. A standard racing bicycle with disk wheels and a standard handlebar was mounted in the test section on a bicycle stand (Fig. 1), with both wheels fixed. The velocity profile in the test section was uniform except for the thin boundary layers on the walls. The stand was placed on a circular force platform. This platform was positioned at $0.1 \mathrm{~m}$ from the lower wind-tunnel wall, for the bicycle to be outside of the boundary layer on this wall, because this boundary layer is also not present in reality, i.e. on the road surface, if there is no wind flow. A positioning 
system for the cyclist was mounted on the bicycle in order to ensure that the cyclist's position was kept constant during the tests and that this position was reproducible for 3D scanning for the CFD model afterwards. Three different "static" positions, i.e. without pedalling, were investigated (Fig. 2), namely the upright position (UP), the dropped position with straight arms (DP) and the time-trial position (TTP). For the TTP, a time-trial handlebar was mounted. For all cyclist positions, the wind direction was parallel to the bicycle axis, representing a head wind. The frontal areas for these positions are $0.41,0.37$ and $0.34 \mathrm{~m}^{2}$, respectively. This corresponds to blockage ratios of $6.1 \%, 5.5 \%$ and $5.0 \%$, respectively. The height and the weight of the cyclist (Person A) were $183 \mathrm{~cm}$ and $72 \mathrm{~kg}$, respectively. He was equipped with an aerodynamic helmet, glasses, gloves and a standard tight-fitting racing suit with long sleeves. Measurements were carried out at three wind speeds, namely 10, 15 and $20 \mathrm{~m} / \mathrm{s}$, in order to identify possible Reynolds number effects. The turbulence intensity at the inlet of the test section was $0.02 \%$, which is very low and which is attributed to the large contraction ratio (of 9) and the presence of screens and honeycombs as flow-conditioning devices in the settling chamber of the wind tunnel. Note that the approach-flow conditions in the wind-tunnel tests in this study and in most other wind-tunnel experiments on cyclist aerodynamics (i.e. uniform mean velocity profile and low turbulence intensity) are representative for the case where only the cyclist is moving and where the speed of the surrounding air is zero. This situation is typically found in indoor environments (e.g. a velodrome) or outdoor in the absence of wind. Note that additionally, measurements were also made of the drag of the circular platform with stand (without cyclist body and bicycle) and of the platform with stand, bicycle and positioning system (without cyclist body).

Aerodynamic drag in cycling is often quantified by the drag area $\mathrm{AC}_{\mathrm{D}}\left(\mathrm{m}^{2}\right)$, which is the product of the frontal area of the cyclist $(A)$ and the drag coefficient $\left(C_{D}\right)$. It relates the drag force $\left(F_{D}\right)$ to the dynamic pressure $\left(\rho U_{\infty}^{2} / 2\right)$ :

$F_{D}=A C_{D} \frac{\rho U_{\infty}^{2}}{2}$

where $\rho$ is the density of air $\left(\mathrm{kg} / \mathrm{m}^{3}\right)$ and $U_{\infty}$ the approach-flow air speed $(\mathrm{m} / \mathrm{s})$. The drag force, i.e. the horizontal component parallel to the wind direction and bicycle, was measured using a force transducer with a precision of $0.05 \mathrm{~N}$, i.e. $0.0008 \mathrm{~m}^{2}$ for the drag area $\mathrm{AC}_{\mathrm{D}}$ at $10 \mathrm{~m} / \mathrm{s}(+/-0.5 \%)$. The data were sampled at $10 \mathrm{~Hz}$ for $25 \mathrm{~s}$. The measurement results will be reported together with the simulation results in the next sections.

\subsection{Wind-tunnel experiments for two drafting cyclists}

The measurements for the two cyclists (Persons B and C) together were performed in the same LST wind tunnel, at a wind speed of about $20 \mathrm{~m} / \mathrm{s}$. These measurements were performed specifically to assess the aerodynamic drag effect of a trailing cyclist on a leading cyclist. The tests were performed with standard race bicycles with the wheels fixed and mounted on a stand. The leading cyclist was positioned on the circular force platform while the trailing cyclist was positioned behind the leading one on two elevated blocks, to ensure that the bicycles were at the same height. The two bicycles were positioned in the same vertical plane, parallel to the wind direction, with a separation (wheel-to-wheel) distance $\mathrm{d}=0.15 \mathrm{~m}$. Persons $\mathrm{B}$ and $\mathrm{C}$ had very similar anthropometric characteristics, but slightly different from the smaller/lighter Person A in the previous wind-tunnel tests (Person B: height $1.91 \mathrm{~m}$, weight $81 \mathrm{~kg}$; Person C: height $1.90 \mathrm{~m}$, weight $81 \mathrm{~kg}$ ). Persons B and C were both equipped with a regular (not time-trial) helmet and a standard racing suit with long sleeves. Measurements were only made for both cyclists in DP. Additionally, measurements were also made of the drag of the circular platform with stand (without cyclist body and bicycle) and of the platform with stand and bicycle (without cyclist body). The measurement results will be reported together with the simulation results in the next sections.

\section{Numerical simulations: computational settings and parameters}

\subsection{Computational geometry and domain}

Digital models of the cyclist (Person A) were obtained with high-resolution 3D laser scanning (K-Scan, Nikon Metrology, Belgium) capturing the specific body characteristics of the cyclist in UP, DP and TTP. For grid generation, surface details were smoothed out to some extent and the bicycle was not included in the computational model. For each position, simulations were performed for a single cyclist and for the two cyclists together, placed exactly behind each other, with separation distance $\mathrm{d}$ of $0.01 \mathrm{~m}, 0.25 \mathrm{~m}, 0.50 \mathrm{~m}$ and $1 \mathrm{~m}$ (Figs. 3). Both virtual cyclists had exactly the same body geometry (i.e. that of Person A) and position on the bicycle.

The cyclists were placed in a computational domain with size according to best practice guidelines $[25,26]$. Note that the CFD simulations only consider the body of the cyclist, not the bicycle configuration (bicycle, stand and force platform). The size of the computational domain was $\mathrm{L} \times \mathrm{W} \times \mathrm{H}=20.9 \times 6 \times 7 \mathrm{~m}^{3}$ for the single cyclist (Fig. 4) and the same for the two cyclists with separation distance $\mathrm{d}=0.01 \mathrm{~m}$. For the other separation 
distances, the length $\mathrm{L}$ of the computational domain was extended accordingly. The maximum blockage ratio was $1 \%$ (for the upright position), which is well below the recommended maximum value of $3 \%$ [25,26]. The distance of the inlet plane to the single or leading cyclist was chosen sufficiently large (i.e. $2.5 \mathrm{~m}$ ) in order to have no pressure gradients in/near the inlet plane.

\subsection{Computational grid}

The grids were based on grid-sensitivity analysis and grid-generation guidelines in CFD [25-31]. Very small prismatic cells were used in the boundary-layer region, with the wall-adjacent cell centre point at only $15 \mu \mathrm{m}$ from the body surface. This high resolution was needed to fully resolve the thin boundary layer at the body with low-Reynolds number modelling (LRNM). LRNM refers to resolving the whole boundary layer down to the viscous sublayer. This is important because boundary layer separation from the surface determines to a large extent the aerodynamic drag. Because the thickness of the viscous sublayer decreases with increasing flow Re number and the Re numbers for airflow around cyclists are quite large (about $10^{6}$ ), the viscous sublayer at the cyclist body surface is very thin (about $1 \mathrm{~mm}$ to $1 \mathrm{~cm}$ ). As a result, a very high grid resolution is required close to the walls. This requirement is often expressed by stating that the dimensionless wall unit $\mathrm{y}^{*}$ needs to be around 1, and certainly smaller than 5, to have at least a few cells in the viscous sublayer. The dimensionless wall unit is defined as:

$\mathrm{y}^{*}=\frac{\mathrm{u}^{*} \mathrm{y}_{\mathrm{P}}}{v}$

where $\mathrm{u}^{*}$ is a friction velocity based on the turbulent kinetic energy $\mathrm{k}_{\mathrm{P}}$ in the wall-adjacent cell centre point $\mathrm{P}$ and on the constant $\mathrm{C}_{\mu}(=0.09)$ :

$\mathrm{u}^{*}=\mathrm{C}_{\mu}^{1 / 4} \mathrm{k}_{\mathrm{P}}^{1 / 2}$

Note that often the parameters $\mathrm{y}^{+}$and $\mathrm{u}^{+}$are used instead of $\mathrm{y}^{*}$ and $\mathrm{u}^{*}$. However, the alternatively defined parameters $\mathrm{y}^{*}$ and $\mathrm{u}^{*}$ have the advantage that they allow to specify grid resolution requirements even at locations in the flow field where the shear stress $\tau_{\mathrm{w}}$ is zero, which occurs at stagnation and reattachment points, i.e. at the cyclists arms, legs, chest, face and helmet. In that case, $\mathrm{y}^{+}$is zero irrespective of the local grid resolution $\mathrm{y}_{\mathrm{P}}$, and cannot be used to specify the grid requirements The alternative parameter $\mathrm{y}^{*}$, however, will not be zero because it is based on $\mathrm{k}_{\mathrm{P}}$ [27-29]. While $30 \mu \mathrm{m}$ cells are used at the body surface, further away from the surface, tetrahedral cells were used with an average cell size of about $0.03 \mathrm{~m}$. The grids for the single cyclists contained about $7.7 \times 10^{6}$ cells versus about $12.0 \times 10^{6}$ cells for the two cyclists. Figure 5a-c display part of the grids for the drafting cyclists in UP, DP and TTP, respectively. The footprints of the cells on the cyclist bodies and the cells in the vertical centre plane are shown. Figure 5d provides a detailed view of the mesh around the head and helmet. The figures illustrate the very high grid resolution close to the body.

\subsection{Boundary conditions}

At the inlet, a uniform velocity of $15 \mathrm{~m} / \mathrm{s}$ was imposed with a turbulence intensity of $0.02 \%$, as in the windtunnel experiments, representing the relative air movement due to cycling at this velocity in still air (zero wind speed). The cyclist body surface was modelled as a no-slip boundary wall with zero roughness. For the bottom, side and top boundaries of the domain, a slip-wall boundary (symmetry) was used. Slip walls assume that the normal velocity component and the normal gradients at the boundary are zero, resulting in flow parallel to the boundary. At the outlet of the computational domain, ambient static pressure was imposed (see Fig. 4).

\subsection{Governing equations and solver settings}

The 3D steady Reynolds-averaged Navier-Stokes (RANS) equations were solved with the standard k- $\varepsilon$ model [32] and with near-wall modelling by LRNM with the one-equation Wolfshtein model [33]. The choice of the standard $\mathrm{k}-\varepsilon$ model was made based on a previous extensive validation study for the aerodynamics of a single cyclist, including the standard, realizable and Re-normalization Group (RNG) k- $\varepsilon$ model, the standard k- $\omega$ model, the Shear-Stress Transport (SST) k- $\omega$ model and Large Eddy Simulation. This study, reported in [8], showed that the k- $\varepsilon$ model most accurately predicted the aerodynamic drag, with an underestimation of $4 \%$ compared to the corresponding wind tunnel result.

Pressure-velocity coupling was taken care of by the SIMPLE algorithm, pressure interpolation was second order and second-order discretisation schemes were used for both the convection terms and the viscous terms of the governing equations. Gradients are computed with the least-squares cell-based method [34], which is 
different from earlier simulations in cycling aerodynamics that used the Green-Gauss cell-based method $[7,8]$. The simulations were performed with the commercial CFD code ANSYS Fluent 12 [34], which uses the control volume method. Convergence was monitored carefully and the iterations were terminated when all residuals showed no further reduction with increasing number of iterations. At this stage, the scaled residuals were about $10^{-4}$ for continuity, $10^{-7}$ for momentum, $10^{-6}$ for turbulent kinetic energy and $10^{-4}$ for turbulence dissipation rate.

\section{Numerical simulations: drag results and validation}

\subsection{Isolated cyclist}

The drag results are summarised in Table 1. As mentioned before, the CFD simulations only considered the body of the cyclist, not the bicycle configuration (bicycle, stand and force platform). Therefore, the experimental drag area of the cyclist's body is obtained by subtracting the drag area of the bicycle configuration and force platform (Fig. 1), which was measured separately, from the total drag area of the cyclist's body, bicycle configuration and force platform. The comparison shows a deviation of $10.5 \%$ for the UP, $3.5 \%$ for the DP and $0.7 \%$ for the TTP. It could be argued that the larger deviations for the less streamlined positions (UP and DP) are related to the more pronounced flow separation for these positions, which is more difficult to reproduce numerically. However, given the very low percentage deviation for TTP, it is very likely that some errors have balanced each other. It should be noted that an error is introduced in the experimental results by subtracting the drag area of the bicycle configuration from the total drag area, because this ignores the interference drag between bicycle and body. Nevertheless, the agreement between the CFD simulations and the wind-tunnel measurements is considered to be very good, which justifies using the same computational settings and parameters (grid, turbulence model, LRNM, etc.) for the simulations of the two drafting cyclists.

\subsection{Two drafting cyclists}

The drag simulation results for the UP, DP and TTP are listed in Tables 2-4 and are graphically represented in Figure 6. The tables show the drag areas of the leading and trailing cyclist as well as the drag (area) reduction due to drafting. The drag reductions are calculated relative to the drag area of the single cyclist in the same position (UP, DP or TTP). The drag reductions for the trailing cyclist are largest for the UP and lowest for the TTP. This is attributed to the fact that the TTP is the most streamlined position and this position of the leading cyclist therefore provides a stronger exposure of the trailing cyclist to the wind. This exposure of the trailing cyclist is less for the DP and UP positions, where flow disturbance and separation are more pronounced. Tables 2-4 also systematically show a drag reduction for the leading cyclist. This reduction however is largest for the TTP and smallest for the UP. Although the drag reductions for the leading cyclist are very small compared to those for the trailing cyclist, it should be noted that these values (up to 2.6\%) are significant, considering the fact that team time trials are sometimes won with only a few seconds difference. Furthermore, for all positions (UP, DP, TTP), the drag reductions for both cyclists decrease with increasing separation distance. Linear interpolation in Table 3 yields a drag reduction for the leading cyclist of $1.3 \%$ for DP and $\mathrm{d}=0.15 \mathrm{~m}$, which corresponds quite well to the value of $1.6 \%$ from the wind-tunnel measurements (Fig. 6). The difference can be attributed to the slightly different body geometry of the cyclists (Body of Person A in the CFD simulations versus Bodies of Persons $\mathrm{B}$ and $\mathrm{C}$ in the wind-tunnel measurements of the two drafting cyclists). Note that while extensive experimental testing was performed for the case of the isolated cyclist for the basic validation study, limitations in resources unfortunately yielded only one series of measurements for the two drafting cyclists (i.e. in DP with $\mathrm{d}=0.15 \mathrm{~m}$ ). In the next section, the CFD results are used to analyze the static pressures around the cyclist(s) and on the cyclist bodies and to explain the drag reduction of both cyclists.

\section{Numerical simulations: analysis of pressure fields}

Figure 7 shows the pressure coefficient $C_{p}$ in the vertical centre plane, for the isolated cyclist and the two drafting cyclists (with $\mathrm{d}=0.01 \mathrm{~m}$ ) and for each of the three positions. Figure 8 shows the same, but in a horizontal plane at waist height of the cyclist. The pressure coefficient is defined as:

$$
\mathrm{C}_{\mathrm{P}}=2 \frac{\mathrm{P}-\mathrm{P}_{0}}{\rho \mathrm{U}_{\infty}^{2}}
$$

where $\mathrm{P}$ is the static pressure and $\mathrm{P}_{0}$ the reference static pressure (= atmospheric pressure). The legend in Figures 7 and 8 has been limited to the interval $[-0.05 ; 0.1]$, to more clearly highlight the changes in the static pressure field due to drafting. Note that the actual maximum and minimum (absolute) values of $C_{p}$ are much larger. The figures clearly show the area of overpressure in front of the cyclists and the area of underpressure behind them. 
For the isolated cyclist, the extent of the overpressure area in front of the cyclist decreases as the position changes from UP over DP to TTP. In case of the two drafting cyclists, the area of underpressure behind the leading cyclist interacts with the area of overpressure in front of the trailing cyclist, which results in a decrease of the underpressure area behind the leading cyclist. As the position of the cyclists changes from UP over DP to TTP, the overpressure area in front of the trailing cyclist gets less extended in the vertical direction but more extended in the horizontal direction, and it moves closer to the leading cyclist. This explains the - at first sight maybe counterintuitive - observation that the benefit for the leading rider is larger for the most aerodynamic (TTP) position. The effect of the presence of the trailing cyclist on the drag of the leading cyclist seems strikingly similar to the statement by Olds [19] in section 1, referring to the low pressure area behind the leading cyclist that is - to some extent - "filled up" by the trailing cyclist.

Figures 9-11 display $C_{p}$ on the cyclist body/bodies. Also here, the colourbar range has been limited to more clearly illustrate the subtle changes in the pressure field. In addition, the local minimum (of negative $\mathrm{C}_{\mathrm{p}}$ ) at the cyclists' back is indicated in the text box. The following observations are made:

- The presence of the trailing cyclist reduces the absolute value of the underpressure at the back of the leading cyclist, leading to a drag reduction of the leading cyclist.

- The presence of the leading cyclist reduces the absolute value of the underpressure at the back of the trailing cyclist. Therefore, the drag reduction of the trailing cyclist is not only caused by decreased overpressure on his frontal surfaces, but also by the decreased underpressure at his back surface.

- Comparing Figures 9, 10 and 11 shows that the values of $C_{P}$ on the cyclists' back decrease monotonically as the position becomes more aerodynamic.

\section{Discussion}

\subsection{Limitations and further research}

To the best knowledge of the authors, a detailed CFD analysis of the effects of drafting cyclists has not yet been published. The present study is based on high-resolution CFD simulations and on validation with wind-tunnel measurements. The CFD study allows assessing and explaining the aerodynamic drag effects of drafting, which include not only the well-known drag reduction of the trailing cyclist but also the less well-known drag reduction of the leading cyclist. However, the present study is also subjected to some important limitations, which are briefly mentioned below, together with some directions for future research.

A main limitation of the study is that the bicycle wheels and cyclist legs were stationary, so only static air resistance was considered. This is important, because under normal circumstances the rotation of the legs disturbs the airstream, which probably at least partly explains the overall smaller differences in drag area reductions in the present study (max. 30\%) compared to previous studies, as mentioned in the introduction (e.g. $37 \%-49 \%$ in the study by Zdravkovich et al. [18]). Future research should focus on analysing the drag reductions at different pedalling frequencies.

The CFD simulations and the resulting drag reductions in the present study were related to the cyclist body only, i.e. without the bicycle. It is known that the bicycle accounts for $30-35 \%$ of the total drag (body + bicycle) [7]. Therefore future work should analyse the drag reductions by taking into account the bicycles as well. Modelling bicycles in CFD is less straightforward, due to the large amount of small details (such as spokes) that will consume many grid cells. To avoid this, one could choose to model either only the main bicycle parts (such as frame, wheels without spokes) or to resort to wind-tunnel testing.

The cross-section of the computational domain in the study was larger than the cross-section of the wind tunnel. While the former yielded a maximum blockage ratio (BR) of $1 \%$, the latter provided a maximum BR of $6.1 \%$. The BR in the CFD simulations was taken lower than the recommended maximum value of $3 \%[25,26]$ to obtain results free of blockage effects that are representative of reality where blockage is absent. On the other hand, the BR in the wind-tunnel measurements was limited by the size of the wind tunnel. The values of 5-6\% are close to the recommended maximum of 5\% in wind-tunnel studies focused on buildings and structures [35].It should be noted that for more aerodynamic shapes, such as cyclists, larger values might be allowed. To evaluate this and to assess the effects of blockage, additional simulations were made where the cross-section of the computational domain was identical to that of the wind tunnel. The increases in drag force or drag ratio compared to the simulations without blockage are $1.2 \%, 0.8 \%$ and $0.2 \%$ for UP, DP and TTP, respectively, which are considered very small.

The present study only considered two drafting cyclists. Further research will consist of extending the aerodynamic analysis with larger groups of drafting cyclists. An addition limitation/assumption in the CFD simulations with LRNM is that the cyclist surface is assumed to be perfectly smooth, which it is not in reality. The favourable comparison with the wind-tunnel experiments however indicates that this assumption does not lead to large discrepancies in the total drag area of the cyclists. 


\subsection{Potential benefits for team time trials}

Based on the calculated drag reduction for the leading cyclist, the "virtual gain" in time or distance by a leading cyclist due to a cyclist drafting in his/her wake can be estimated. Also, some considerations about optimum team time-trial strategy can be made. Table 5 shows the estimated virtual gain in time and travelled distance for the leading rider based on the drag reduction of $2.6 \%$, for a typical team time-trial cycling speed of $15 \mathrm{~m} / \mathrm{s}(54 \mathrm{~km} / \mathrm{h})$ and for total team time-trial distances of $10 \mathrm{~km}$ up to $70 \mathrm{~km}$. Note that a $67.5 \mathrm{~km}$ team time trial was included in the 2005 Tour de France. The virtual time gain ranges from $9 \mathrm{~s}$ up to $60 \mathrm{~s}$. These time differences are large, considering the fact that in elite race cycling, team time-trial stages are often won based on a few tens of seconds. Note however that these estimates are only "virtual gains", because in every team time trial and irrespective of the order of the cyclists, a drag reduction for the leading cyclist will be present, provided that all cyclists ride sufficiently close to each other. However, it should also be noted that all percentages and virtual time gain estimates in this study were based on drafting cyclists in which both cyclists have exactly the same body geometry. Given the results in sections 4 and 5 , it can be assumed that a leading cyclist will experience a larger drag reduction when a taller or wider cyclist is drafting in his/her wake, and that (s)he will experience a lower drag reduction when a smaller or more slender cyclist occupies his/her wake. This implies that there is an optimum strategy for team time trials, which should be determined not only based on the power performance but also on the body geometry, rider sequence and resulting aerodynamic drag of each team member.

\section{Summary and conclusions}

The aerodynamic drag of two drafting cyclists in upright position (UP), dropped position (DP) and time-trial position (TTP) has been analysed by Computational Fluid Dynamics (CFD) simulations supported by windtunnel measurements. Simulations have been made for single (isolated) cyclists and for two drafting cyclists with bicycle separation distances (d) from $0.01 \mathrm{~m}$ to $1 \mathrm{~m}$. For the isolated cyclist, the differences between the measured and numerically simulated drag areas are $10.5 \%, 3.5 \%$ and $0.7 \%$ for UP, DP and TTP, respectively, which is considered a good agreement. Compared to an isolated cyclist and for $\mathrm{d}=0.01 \mathrm{~m}$, the drag reduction of the trailing cyclist is $27.1 \%, 23.1 \%$ and $13.8 \%$ for UP, DP and TTP, respectively. Compared to an isolated cyclist and for $\mathrm{d}=0.01 \mathrm{~m}$, the drag reduction of the leading cyclist is $0.8 \%, 1.7 \%$ and $2.6 \%$ for UP, DP and TTP, respectively. Apart from the well-known drag reduction for the trailing cyclist, this study also confirms and quantifies the drag reduction for the leading cyclist. This effect was also confirmed by the wind-tunnel measurements: for DP with $\mathrm{d}=0.15 \mathrm{~m}$, the measured drag reduction of the leading cyclist was $1.6 \%$ versus $1.3 \%$ by CFD simulation. The CFD simulations have been used to explain the aerodynamic drag effects by means of the detailed static pressure distribution on and around the cyclists. It is shown that both cyclists significantly influence the static pressure in the region between them and the pressure distribution on each other's body, which governs the drag reduction experienced by each cyclist.

The main limitation of the study is that only "static" positions have been evaluated, i.e. with fixed bicycle wheels and cyclist legs. In spite of this limitation, the study has provided additional insight in the aerodynamic drag effects of drafting. Four specific aerodynamic effects have been observed:

1. The leading cyclist not only reduces the overpressure in front of the trailing cyclist, but also reduces the absolute value of the underpressure at the back of the trailing cyclist. Both effects contribute to the drag reduction of the trailing cyclist.

2. The presence of the trailing cyclist reduces the absolute value of the underpressure at the back of the leading cyclist and therefore yields a drag reduction for the leading cyclist. This confirms the earlier mentioned statement by Olds [19] about the trailing rider "filling up" the low pressure area behind the leading one.

3. The drag reduction for the trailing cyclist decreases as the position gets more aerodynamic (from UP to TTP), due to the larger exposure of the trailing cyclist to the wind.

4. The drag reduction for the leading cyclist increases as the position gets more aerodynamic, due to the closer position of the overpressure area in front of the trailing cyclist to the leading cyclist.

These results imply that there is an optimum strategy for team time trials, which should be determined not only based on the power performance but also on the body geometry, rider sequence and the resulting aerodynamic drag of each team member. Similar studies can be performed for other sports such as skating, swimming and running.

\section{Acknowledgements}

The hardware support of the Laboratory of the Unit Building Physics and Services for the CFD simulations and the high-quality assistance of the Dutch-German Wind Tunnel team (DNW) headed by Ir. Eddy Willemsen for 
the wind-tunnel measurements are gratefully acknowledged. Thijs Defraeye is a postdoctoral fellow of the Research Foundation - Flanders (FWO) and gratefully acknowledges its support.

\section{References}

[1] Wilson DG. 2004. Bicycling science. Third Edition, Cambridge, MA: MIT Press.

[2] Kyle CR, Burke ER. 1984. Improving the racing bicycle. Mech Eng 106(9), 34-45.

[3] Grappe G, Candau R, Belli A, Rouillon JD. 1997. Aerodynamic drag in field cycling with special reference to the Obree's position. Ergonomics 40(12), 1299-1311.

[4] Lukes RA, Chin SB, Haake SJ. 2005. The understanding and development of cycling aerodynamics. Sports Eng 8, 59-74.

[5] Hanna RK. 2002. Can CFD make a performance difference in sport?. In: Ujihashi, S., Haake, S.J. (Eds.), The Engineering of Sport 4. Blackwell Science, Oxford, pp. 17-30.

[6] Lukes RA, Hart JH, Chin SB, Haake SJ. 2004. The aerodynamics of mountain bicycles: The role of computational fluid dynamics. In: Hubbard M, Mehta RD, Pallis JM. (Eds.), The Engineering of Sport 5. International Sports Eng Association, Sheffield.

[7] Defraeye T, Blocken B, Koninckx E, Hespel P, Carmeliet J. 2010. Aerodynamic study of different cyclist positions: CFD analysis and full-scale wind-tunnel tests. J Biomech 43(7), 1262-1268.

[8] Defraeye T, Blocken B, Koninckx E, Hespel P, Carmeliet J. 2010. Computational Fluid Dynamics analysis of cyclist aerodynamics: Performance of different turbulence-modelling and boundary-layer modelling approaches. J Biomech 43(12), 2281-2287.

[9] Defraeye T, Blocken B, Koninckx E, Hespel P, Carmeliet J. 2011. Computational fluid dynamics analysis of drag and convective heat transfer of individual body segments for different cyclist positions. J Biomech 44(9), 1695-1701.

[10] Dabnichki P, Avital E. 2006. Influence of the position of crew members on aerodynamics performance of a two-man bobsleigh. J Biomech 39 (15), 2733-2742.

[11] Lecrivain G, Slaouti A, Payton C, Kennedy I. 2008. Using reverse engineering and computational fluid dynamics to investigate a lower arm amputee swimmer's performance. J Biomech 41(13), 2855-2859.

[12] Zaïdi H, Taiar R, Fohanno S, Polidori G. 2008. Analysis of the effect of swimmer's head position on swimming performance using computational fluid dynamics. J Biomech 41(6), 1350-1358.

[13] Minetti AE, Machtsiras G, Masters JC. 2009. The optimum finger spacing in human swimming. J Biomech 42, 2188-2190.

[14] Zaïdi H, Fohanno S, Taiar R, Polidori G. 2010. Turbulence model choice for the calculation of drag forces when using the CFD method. J Biomech 43(3), 405-411.

[15] Kyle CR. 1979. Reduction of wind resistance and power output of racing cyclists and runnings travelling in groups. Ergonomics 22(4), 387-397.

[16] McCole SD, Claney K, Conte J-C, Anderson R, Hagberg JM. 1990. Energy expenditure during bicycling. J Appl Physiol 68(2), 748-753.

[17] Hagberg JM, McCole SD. 1990. The effect of drafting and aerodynamic equipment on the energy expenditure during cycling. Cycling Science 2(3), 19-22.

[18] Zdravkovich MM, Ashcroft MW, Chisholm SJ, Hicks N. 1996. Effect of cyclist's posture and vicinity of another cyclist on aerodynamic drag. The Engineering of Sport. Haake (Ed.), Balkema, Rotterdam, pp. 21-28.

[19] Olds T. 1998. The mathematics of breaking away and chasing in cycling. Eur J Appl Physiol 77: 492-497.

[20] Broker JP, Kyle CR, Burke ER. 1999. Racing cyclist power requirements in the 4000-m individual and team pursuits, Med Sci Sports Exercise 31 (11), 1677-1685.

[21] Edwards AG, Byrnes WC. 2007. Aerodynamic characteristics as determinants of the drafting effect in cycling. Med Sci Sports Exercise 39(1), 170-176.

[22] Iniguez-de-la-Torre A, Iniguez J. 2009. Aerodynamics of a cycling team in a time trial: does the cyclist at the front benefit? Eur J Phys 30: 1365-1369.

[23] Hoerner SF. 1965. Fluid dynamic drag. Bricktown, N.J.

[24] Papadopoulos J, Drela M. 1999. Some comment on the effects of interference drag on two bodies in tandem and side-by-side. Human Power 46, 19-20.

[25] Franke J, Hellsten A, Schlünzen H, Carissimo B. 2007. Best practice guideline for the CFD simulation of flows in the urban environment, COST Action 732: Quality assurance and improvement of microscale meteorological models, Hamburg, Germany.

[26] Tominaga Y, Mochida A, Yoshie R, Kataoka H, Nozu T, Yoshikawa M, Shirasawa T. 2008. AIJ guidelines for practical applications of CFD to pedestrian wind environment around buildings. J Wind Eng Ind Aerodyn 96(10-11), 1749-1761.

[27] Casey M, Wintergerste T. 2000. Best Practice Guidelines. ERCOFTAC Special Interest Group on "Quality and Trust in Industrial CFD", ERCOFTAC. 
[28] Blocken B, Defraeye T, Derome D, Carmeliet J. 2009. High-resolution CFD simulations of forced convective heat transfer coefficients at the facade of a low-rise building. Build Environ 44(12): 2396-2412.

[29] Defraeye T, Blocken B, Carmeliet J. 2010. CFD analysis of convective heat transfer at the surfaces of a cube immersed in a turbulent boundary layer. International Journal of Heat and Mass Transfer 53(1-3), 297-308.

[30] Blocken B, Janssen WD, van Hooff T. 2012. CFD simulation for pedestrian wind comfort and wind safety in urban areas: General decision framework and case study for the Eindhoven University campus. Environ Modell Softw 30, 15-34.

[31] Blocken B, Gualtieri C. 2012. Ten iterative steps for model development and evaluation applied to Computational Fluid Dynamics for Environmental Fluid Mechanics. Environ Modell Softw 33, 1-22.

[32] Jones WP, Launder BE. 1972. The prediction of laminarization with a two-equation model of turbulence. Int J Heat Mass Transfer 15, 301-314.

[33] Wolfshtein M. 1969. The velocity and temperature distribution in one-dimensional flow with turbulence augmentation and pressure gradient. Int J Heat Mass Transfer 12 (3), 301-318.

[34] ANSYS Inc. 2009. ANSYS Fluent 12.0 Theory Guide.

[35] ASCE 1999. Wind tunnel studies of buildings and structures. N. Isyumov (Ed.), ASCE Manuals and Reports on Engineering Practice No.67, American Society of Civil Engineers, 214 pp. 


\section{TABLES}

Table 1: Measured (exp.) drag area $\mathrm{AC}_{\mathrm{D}}$ of cyclist body (Person $\mathrm{A}$ ) and bicycle, measured and simulated (CFD) drag area of cyclist body (Person A) without bicycle, and percentage deviation between measurements and simulations.

\begin{tabular}{ccccc}
\hline & $\begin{array}{c}\mathrm{AC}_{\mathrm{D}_{2} \exp } \\
\text { cyclist body }+ \text { bicycle } \\
\left(\mathrm{m}^{2}\right)\end{array}$ & $\begin{array}{c}\mathrm{AC}_{\mathrm{D}_{-} \exp } \\
\text { cyclist body } \\
\left(\mathrm{m}^{2}\right)\end{array}$ & $\begin{array}{c}\mathrm{AC} C_{\mathrm{D}_{-} \mathrm{CFD}} \\
\text { cyclist body } \\
\left(\mathrm{m}^{2}\right)\end{array}$ & $\begin{array}{c}100\left(\mathrm{AC}_{\mathrm{D}_{-} \exp }-\mathrm{AC}_{\mathrm{D} \_\mathrm{CFD}}\right) / \mathrm{AC}_{\mathrm{D}_{-} \exp } \\
\text { cyclist body } \\
(\%)\end{array}$ \\
\hline $\mathrm{UP}$ & 0.270 & 0.193 & 0.213 & 10.5 \\
$\mathrm{DP}$ & 0.243 & 0.167 & 0.173 & 3.5 \\
$\mathrm{TTP}$ & 0.211 & 0.134 & 0.135 & 0.7 \\
\hline
\end{tabular}

Table 2: CFD results: drag areas and drag area reductions for leading and trailing cyclist (Person A) in upright position (UP), for different bicycle separation distances $d$. The reductions are calculated in comparison with the isolated cyclist (Person A) in UP, with $\mathrm{AC}_{\mathrm{D}}=0.213$.

\begin{tabular}{|c|c|c|c|c|}
\hline (m) & $\begin{array}{c}A C_{D \_ \text {leading }} \\
\left(\mathrm{m}^{2}\right) \\
\end{array}$ & $\begin{array}{c}\mathrm{AC}_{\mathrm{D}_{-} \text {trailing }} \\
\left(\mathrm{m}^{2}\right) \\
\end{array}$ & $\begin{array}{c}100\left(\mathrm{AC}_{\mathrm{D}_{-} \text {leading }}-\mathrm{AC}_{\mathrm{D}_{-} \text {isolated }}\right) / \\
\mathrm{AC}_{\mathrm{D}_{-} \text {isolated }} \\
(\%) \\
\end{array}$ & $\begin{array}{c}100\left(\mathrm{AC}_{\mathrm{D}_{-} \text {trailing }}-\mathrm{AC}_{\mathrm{D}_{-} \text {isolated }}\right) / \\
\mathrm{A} \mathrm{C}_{\mathrm{D}_{-} \text {isolated }} \\
(\%) \\
\end{array}$ \\
\hline 0.01 & 0.211 & 0.155 & 0.8 & 27.1 \\
\hline 0.25 & 0.212 & 0.157 & 0.7 & 26.5 \\
\hline 0.5 & 0.212 & 0.158 & 0.6 & 25.9 \\
\hline 1 & 0.212 & 0.160 & 0.5 & 25.0 \\
\hline
\end{tabular}

Table 3: CFD results: drag areas and drag area reductions for leading and trailing cyclist (Person A) in dropped position (DP), for different bicycle separation distances $\mathrm{d}$. The reductions are calculated in comparison with the isolated cyclist (Person A) in DP, with $\mathrm{AC}_{\mathrm{D}}=0.173$.

\begin{tabular}{|c|c|c|c|c|}
\hline (m) & $\begin{array}{c}\mathrm{AC}_{\mathrm{D} \_ \text {leading }} \\
\left(\mathrm{m}^{2}\right) \\
\end{array}$ & $\begin{array}{c}\mathrm{AC}_{\mathrm{D}_{-} \text {trailing }} \\
\left(\mathrm{m}^{2}\right) \\
\end{array}$ & $\begin{array}{c}100\left(\mathrm{AC}_{\mathrm{D}_{-} \text {leading }}-\mathrm{AC}_{\mathrm{D}_{-} \text {isolated }}\right) / \\
\mathrm{AC}_{\mathrm{D}_{-} \text {isolated }} \\
(\%)\end{array}$ & $\begin{array}{c}100\left(\mathrm{AC}_{\mathrm{D}_{-} \text {trailing }}-\mathrm{AC}_{\mathrm{D}_{-} \text {isolated }}\right) / \\
\mathrm{AC} \mathrm{C}_{\mathrm{D}_{\text {_isolated }}} \\
(\%) \\
\end{array}$ \\
\hline 0.01 & 0.170 & 0.133 & 1.7 & 23.1 \\
\hline 0.25 & 0.171 & 0.133 & 1.1 & 22.9 \\
\hline 0.5 & 0.172 & 0.135 & 0.7 & 22.1 \\
\hline 1 & 0.172 & 0.136 & 0.4 & 21.4 \\
\hline
\end{tabular}

Table 4: Drag areas and drag area reductions for leading and trailing cyclist (Person A) in time-trial position (TTP), for different bicycle separation distances d. The reductions are calculated in comparison with the isolated cyclist (Person A) in TTP, with $\mathrm{AC}_{\mathrm{D}}=0.135$.

\begin{tabular}{ccccc}
\hline $\mathrm{d}$ & $\mathrm{AC}_{\mathrm{D} \_ \text {leading }}$ & $\mathrm{AC}_{\mathrm{D}_{-} \text {trailing }}$ & $\begin{array}{c}100\left(\mathrm{AC}_{\mathrm{D}_{-} \text {leading }}-\mathrm{AC}_{\mathrm{D}_{-} \text {isolated }}\right) / \\
\mathrm{AC}_{\mathrm{D}_{-} \text {isolated }}\end{array}$ & $\begin{array}{c}100\left(\mathrm{AC}_{\mathrm{D}_{-} \text {trailing }}-\mathrm{AC}_{\mathrm{D}_{-} \text {isolated }}\right) / \\
\mathrm{AC}_{\mathrm{D}_{\text {issolated }}}\end{array}$ \\
\hline 0.01 & 0.131 & 0.116 & $(\%)$ & 13.8 \\
0.25 & 0.133 & 0.117 & 2.6 & 13.4 \\
0.5 & 0.133 & 0.118 & 1.7 & 12.8 \\
1 & 0.134 & 0.119 & 1.2 & 11.7 \\
\hline
\end{tabular}

Table 5: Estimated "virtual gain" in time and travelled distance due to the $2.6 \%$ drag reduction of the leading cyclist in TTP, based on an average cycling speed of $15 \mathrm{~m} / \mathrm{s}(54 \mathrm{~km} / \mathrm{h})$.

\begin{tabular}{lccccccc}
\hline Stage distance $(\mathrm{m})$ & 10000 & 20000 & 30000 & 40000 & 50000 & 60000 & 70000 \\
\hline Time gain $(2.6 \%)(\mathrm{s})$ & 9 & 17 & 26 & 34 & 43 & 51 & 60 \\
Distance gain $(2.6 \%)(\mathrm{m})$ & 128 & 255 & 383 & 510 & 638 & 765 & 893 \\
\hline
\end{tabular}




\section{FIGURE CAPTIONS}

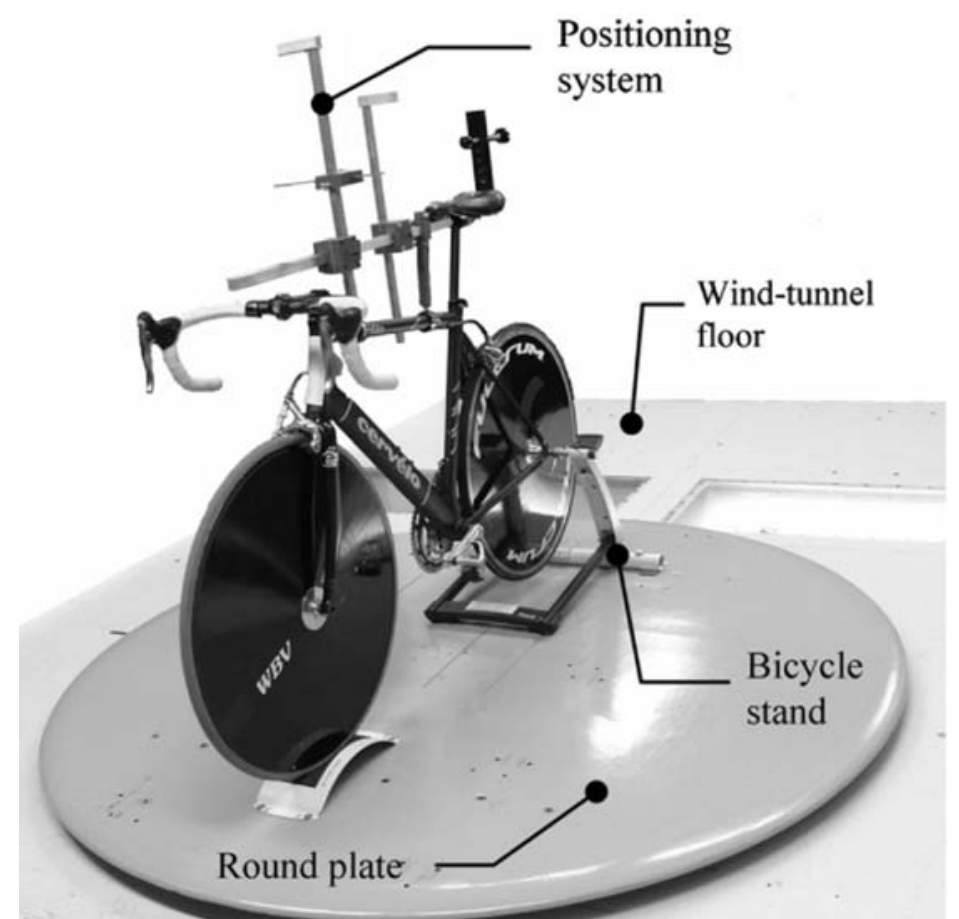

Figure 1. Experimental set-up of force platform (round plate), bicycle stand, bicycle and positioning system.

a

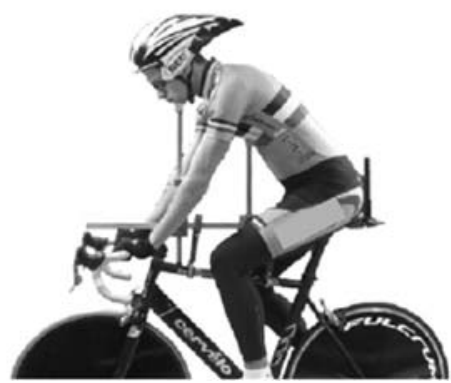

b

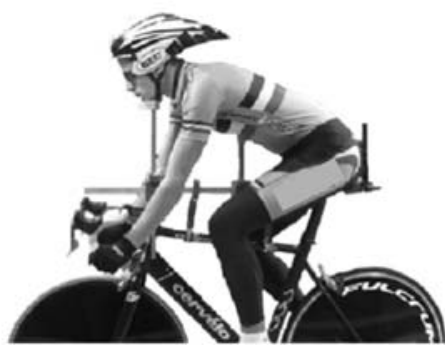

C

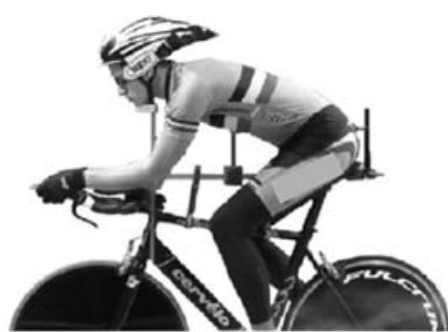

Figure 2. Three cyclist positions (Person A): (a) Upright position (UP); (b) Dropped position (DP); (c) Time-trial position (TTP). 

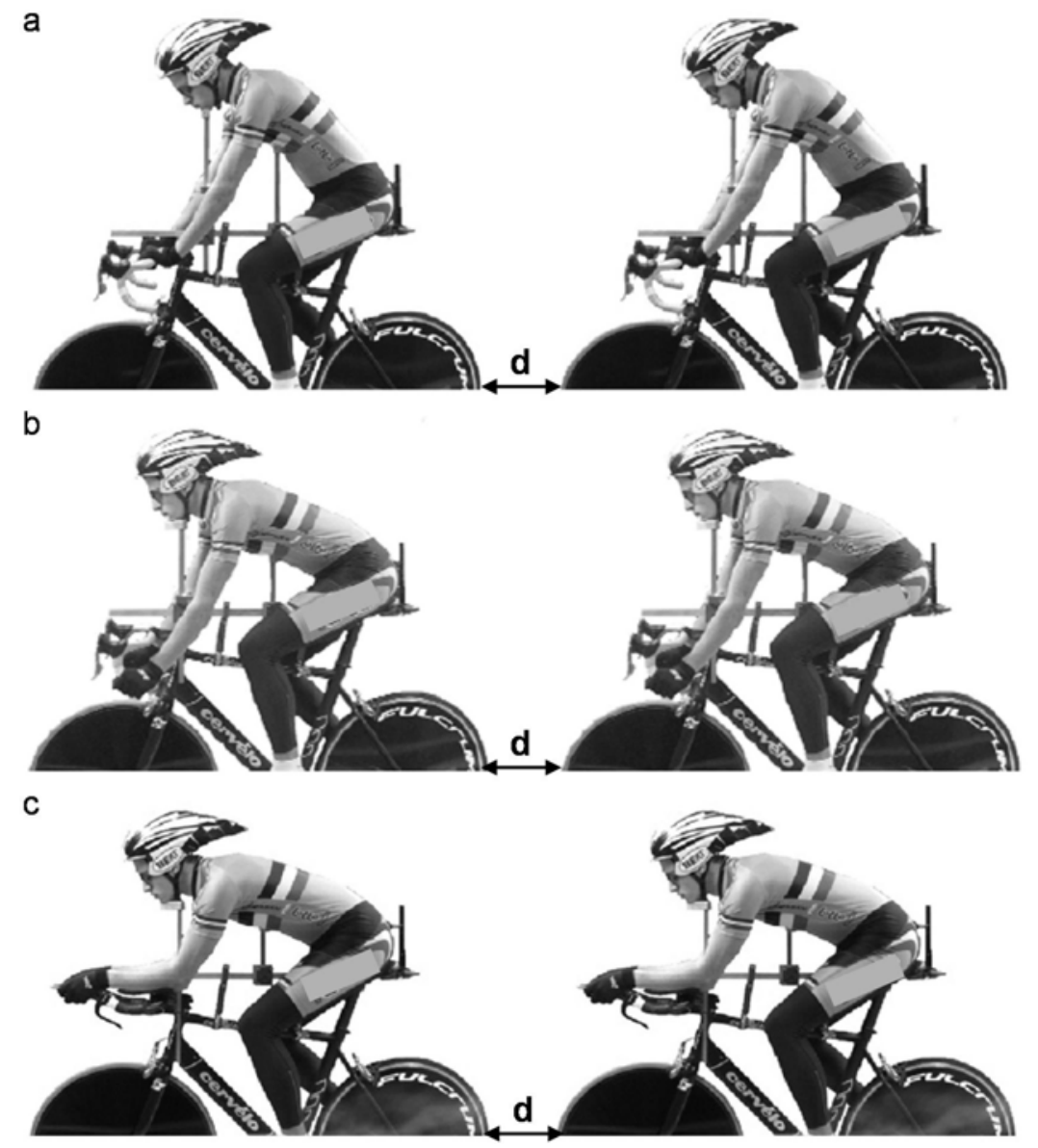

Figure 3. Three positions of two drafting cyclists (Person A) at bicycle separation distance d: (a) Upright position (UP); (b) Dropped position (DP); (c) Time-trial position (TTP).

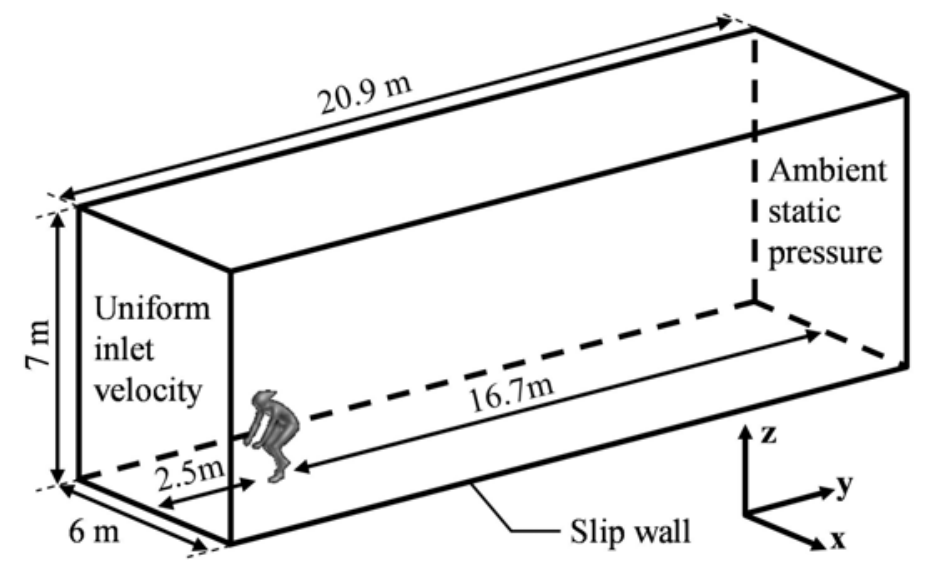

Figure 4. Computational domain and boundary conditions for single (isolated) cyclist. 

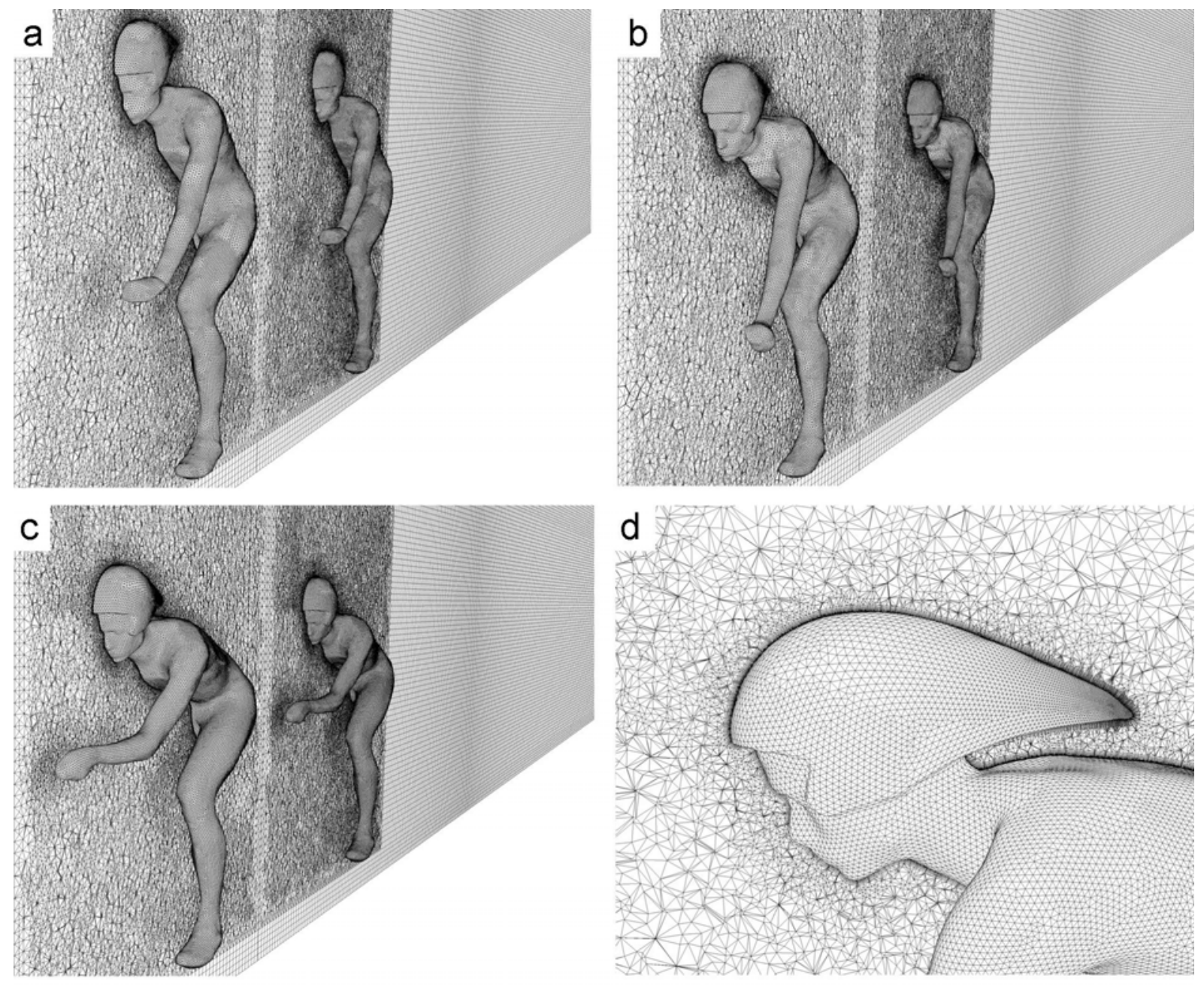

Figure 5. Hybrid computational grid on cyclist bodies and in vertical centreplane for two drafting cyclists (Person A) in TTP at bicycle separation distance $\mathrm{d}=0.01 \mathrm{~m}$.
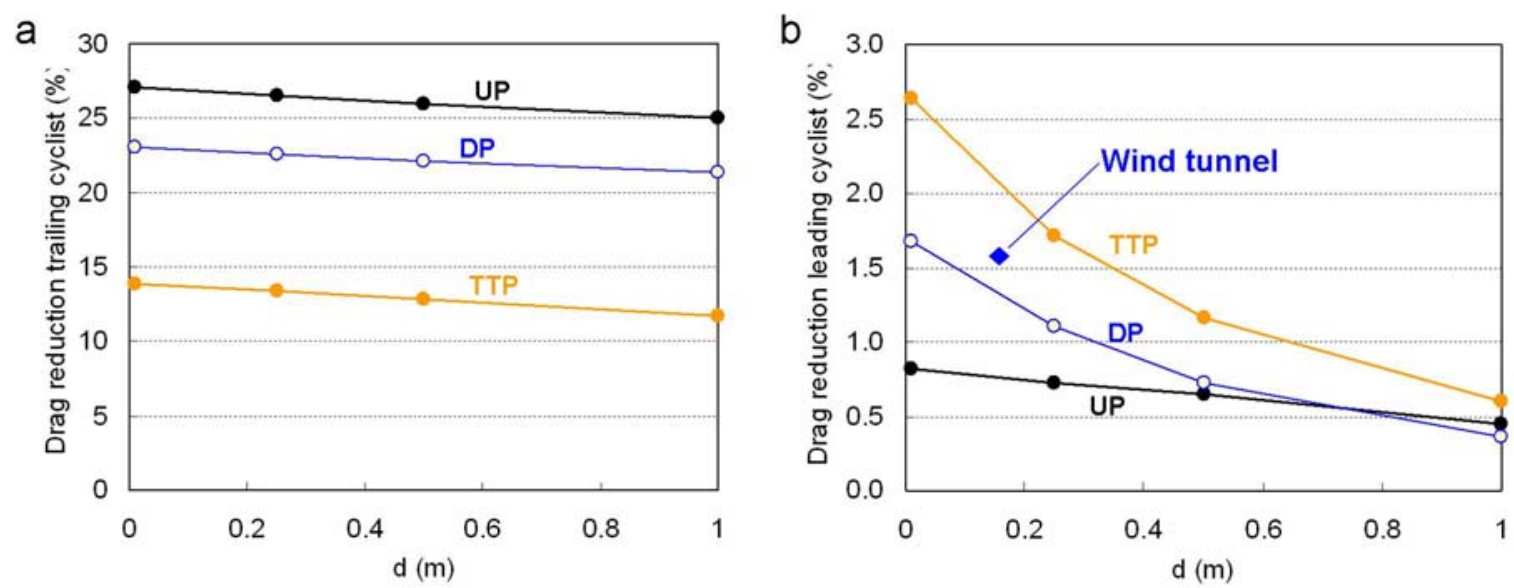

Figure 6. (a) Drag reducting of trailing cyclist for UP, DP and TTP; (b) Drag reduction for leading cyclist for UP, DP and TTP and wind-tunnel measurement result for DP. 

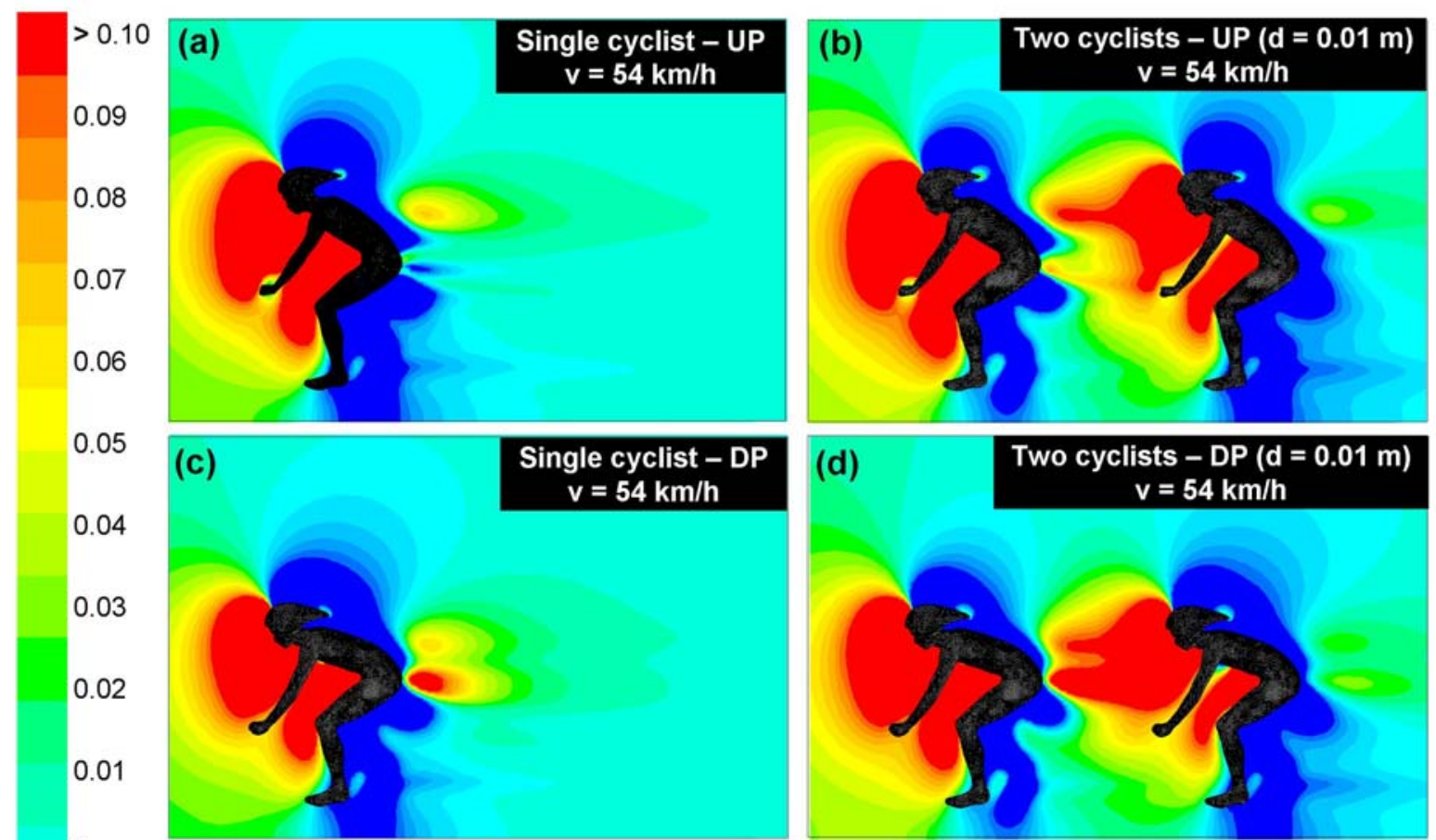

(e)

$-0.01$

$-0.02$

$-0.03$

$-0.04$

$<-0.05$
Single cyclist - TTP $v=54 \mathrm{~km} / \mathrm{h}$
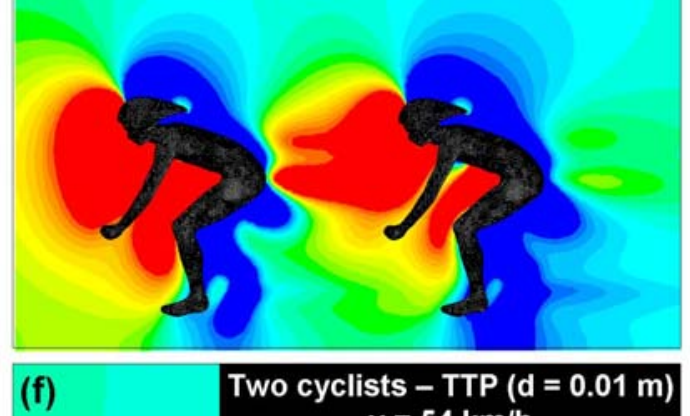
$v=54 \mathrm{~km} / \mathrm{h}$

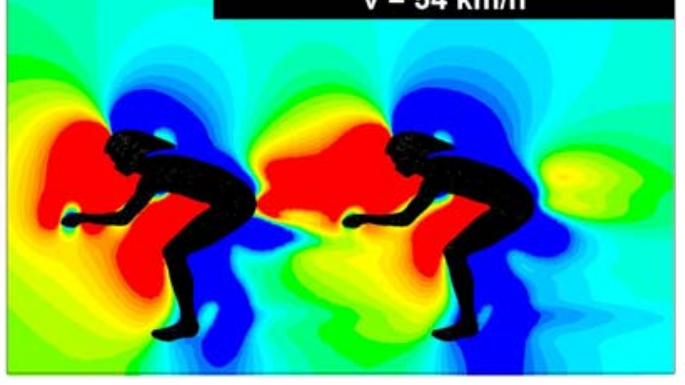

Figure 7. Pressure coefficients $C_{P}$ in the vertical centre plane for single cyclist (left) and two cyclists with bicycle separation distance $\mathrm{d}=0.01 \mathrm{~m}$ (right), at cycling speed of $54 \mathrm{~km} / \mathrm{h}$ for (a-b) upright position (UP); (c-d) dropped position (DP); (e-f) time-trial position (TTP) (Person A). 


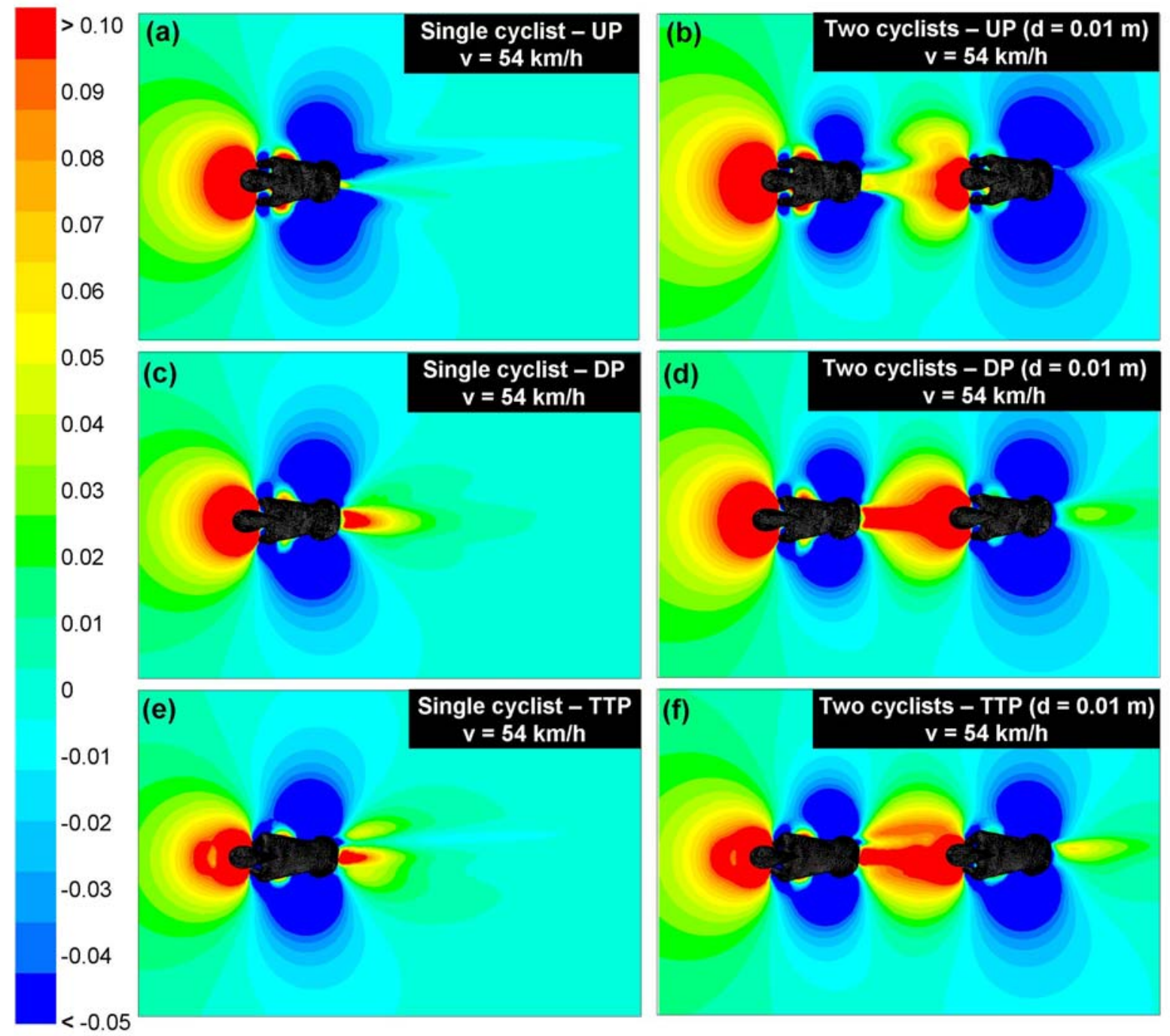

Figure 8. Pressure coefficients $\mathrm{C}_{\mathrm{P}}$ in the horizontal plane at waist height for single cyclist (left) and two cyclists with bicycle separation distance $d=0.01 \mathrm{~m}$ (right), at cycling speed of $54 \mathrm{~km} / \mathrm{h}$ for (a-b) upright position (UP); (c-d) dropped position (DP); (e-f) time-trial position (TTP) (Person A). 




Figure 9. Pressure coefficients $C_{P}$ on cyclist bodies (Person A), for single cyclist (left) and two cyclists (right) in upright position (UP), at cycling speed $54 \mathrm{~km} / \mathrm{h}$ and bicycle separation distance $\mathrm{d}=0.01 \mathrm{~m}$.

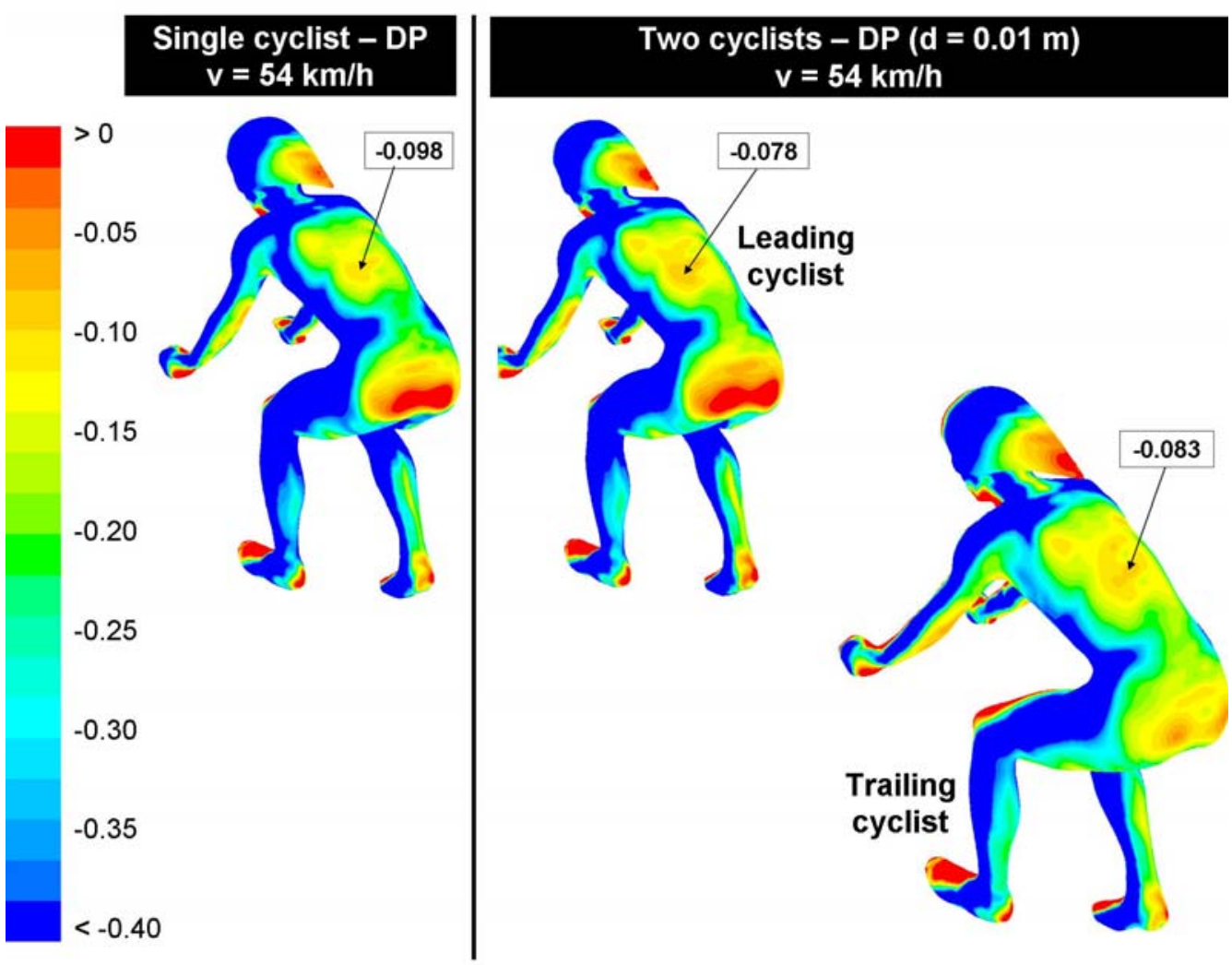

Figure 10. Pressure coefficients $C_{P}$ on the cyclist bodies (Person A), for single cyclist (left) and two cyclists (right) in dropped position (DP), at cycling speed $54 \mathrm{~km} / \mathrm{h}$ and bicycle separation distance $\mathrm{d}=0.01 \mathrm{~m}$. 


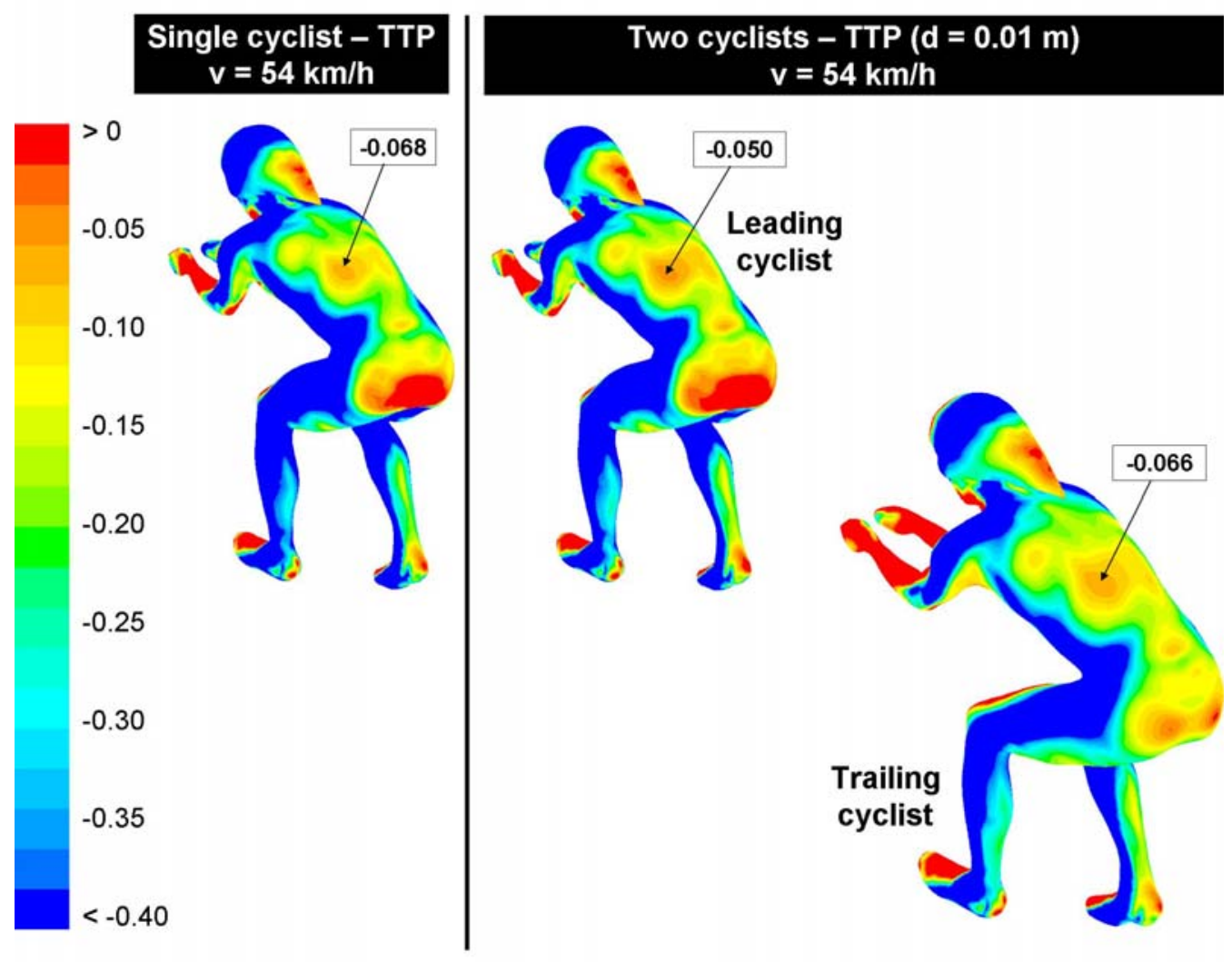

Figure 11. Pressure coefficients $\mathrm{C}_{\mathrm{P}}$ on the cyclist bodies (Person A), for single cyclist (left) and two cyclists (right) in time-trial position (TTP), at cycling speed $54 \mathrm{~km} / \mathrm{h}$ and bicycle separation distance $\mathrm{d}=0.01 \mathrm{~m}$. 